\title{
Examination of the Utility of the High Throughput In Vitro Metabolic Stability Assay to Estimate In Vivo Clearance in the Mouse
}

\author{
S. Sarawek ${ }^{*},{ }^{1}$, L. Li $^{1}$, X.Q. Yu ${ }^{1}$, S. Rooney ${ }^{1}$, A. Nouraldeen ${ }^{1}$, L. Moran ${ }^{1}$, L.A. Rodriguez ${ }^{2}$, J. Zhang $^{3}$ \\ and A.G.E. Wilson ${ }^{1}$
}

\author{
${ }^{I}$ Drug Metabolism, Pharmacokinetics and Toxicology, Lexicon Pharmaceutical Inc., the Woodlands, Texas, USA \\ ${ }^{2}$ Enterprise informatics, Lexicon Pharmaceutical Inc., the Woodlands, Texas, USA \\ ${ }^{3}$ Keystone Analytical, Inc, a PharmaNet Company, 401A Industrial Drive, North Wales, PA, 19454, USA
}

\begin{abstract}
In vitro determination of metabolic stability is routinely used to assess the overall metabolic liability of compounds and for prioritization for in vivo studies. If in vitro metabolic stability data could be used to reliably predict in vivo clearance (CL), it would add significant value in the selection of compounds for in vivo pharmacokinetic and pharmacology studies. We have evaluated the utility of our in vitro metabolic stability screening assay to estimate in vivo CL in the mouse. The in vitro mouse clearances $\left(\mathrm{CL}_{\text {in vitro }}\right)$ of 146 structurally diverse compounds with metabolic stabilities $>30 \%$, were compared to mouse in vivo CL data. Approximately $45 \%$ of the compounds showed agreement between in vivo CL and predicted $\mathrm{CL}_{\text {in vitro }}$ within a 2-fold error criteria. The correlation appeared worse when correction for the extent of incorporation of plasma protein binding or both plasma and S9 bindings (i.e. 14\% and $28 \%$ agreement, respectively). Classification of the compounds into three groups based on in vivo $\mathrm{CL}(<30 \mathrm{~mL} / \mathrm{min} / \mathrm{kg}, 30-70 \mathrm{~mL} / \mathrm{min} / \mathrm{kg}$, and $>70$ $\mathrm{mL} / \mathrm{min} / \mathrm{kg}$ ) did not show any improvement between in vivo $\mathrm{CL}$ and predicted $\mathrm{CL}_{\text {in vitro }}$. The percentage of compounds falling within the 2-fold error criteria for low CL, moderate CL and high CL groups were 54, 31 and $24 \%$, respectively. In conclusion, our analysis suggests that in vitro metabolic stability data, as routinely obtained in early ADME screening protocols, does not demonstrate a strong correlation with or predictivity for, absolute in vivo CL in the mouse.
\end{abstract}

\section{INTRODUCTION}

Drug discovery and development is both time consuming and expensive. A study by Adams and Brantner reported that cost of new drug development can vary from 500 million dollars to more than 2,000 million dollars, depending on the clinical indication, manufacturing, etc [1]. Therefore, to raise the efficiency, and reduce the attrition rate of the drug discovery and development process, a more cost-effective industrial practice is becoming increasingly critical. Determination of the metabolic stability of compounds using in vitro hepatic systems (e.g., S-9 fraction), is now common place in the pharmaceutical and biotechnology industries [2].

It has been suggested that determination of intrinsic CL $\left(\mathrm{CL}_{\text {int }}\right)$ using these in vitro hepatic systems, provides a measure of in vivo CL [3,4]. For example, several studies have reported a good correlation between predicted $\mathrm{CL}_{\text {in vitro }}$ and in vivo $\mathrm{CL}$ using hepatocytes and microsomes [3-5]. However, in contrast, a number of studies have also suggested problems with this approach. For example, Iwatsubo et al. (1997) reported a poor correlation between in vivo $\mathrm{CL}$ and in vitro $\mathrm{CL}_{\text {int }}$ with a number of compounds tested in human liver microsomes [6]. Andersson et al. reported 3 out of 4 compounds with poor predictions of hepatic clearance using human microsomes [7]. Thus, the robustness, accuracy and

*Address correspondence to this author at the Drug Metabolism, Pharmacokinetics, Toxicology and Pathology, Lexicon Pharmaceutical Inc., The Woodlands, Texas, USA; Tel: (281) 8633267 ;

E-mail: ssarawek@yahoo.com precision of using metabolic stability data to predict in vivo $\mathrm{CL}$ remain the subject of significant interest.

High throughput S-9 metabolic stability determination is routinely used within the Pharmaceutical and Biotechnology Industries as a means to identify potential metabolic liabilities at an early stage. The potential of this assay to efficiently investigate the metabolic liability of large numbers of compounds provides significant value in compound prioritization and structure-activity relationships (SAR) for lead identification and optimization. In addition, if this in vitro data were capable of reliably estimating potential in vivo CL over a wide range of chemical structures, it would also be of significant value in the prioritization of compounds for the more time consuming and expensive in vivo pharmacokinetic (PK), pharmacodynamic (PD) and toxicology studies. However, an essential requirement is that the assay and data have relevance to, and robustness, to estimate in vivo CL. In this manuscript, we report on our studies with 146 compounds, in which we have investigated the reliability of the in vitro metabolic stability assay to assess in vivo PK performance, as determined by in vivo $\mathrm{CL}$.

\section{MATERIALS AND METHODS}

\section{Materials}

All reagents used were of standard laboratory reagent grade or better. The 146 structurally diverse test compounds with metabolic stability greater than $30 \%$ were obtained from Lexicon Pharmaceutical Company over the five years. Mouse liver S9 was obtained from Xenotech (Lenexa, KS). 
C57BL/6 albino male mice were bred by Lexicon Pharmaceutical Company.

\section{Metabolic Stability Assay}

The in vitro metabolic stability assay was performed as previously described [8]. Briefly, in one time point study, 146 test compounds at $10 \mu \mathrm{M}$ is mixed with reaction mixture containing $0.45 \mathrm{mg} / \mathrm{mL}$ mouse liver $\mathrm{S} 9$ fraction, $3.3 \mathrm{mM}$ glucose-6-phosphate/magnesium (Sigma Chemicals St. Louis MO), $0.4 \mathrm{U} / \mathrm{mL}$ glucose-6-phosphate dehydrogenase (Sigma Chemicals St. Louis MO). The reaction was initiated by adding $1 \mathrm{mM} \mathrm{NADP}{ }^{+}$(Sigma Chemicals St. Louis MO). After 60 min incubation at $37{ }^{\circ} \mathrm{C}$, the reaction was terminated by adding equal volume of acetonitrile containing $0.5 \mu \mathrm{M}$ verapamil (Sigma Chemicals St. Louis MO) as an internal standard. After protein precipitation, the supernatant was analyzed by LC/MS/MS. In multiple time points study, 27 compounds were selected from 146 compounds and tested at $1 \mu \mathrm{M}$. Reaction was terminated at $0,10,30$, and 60 min respectively. Beside time point studies, substrate concentration study was performed using one time point method. 35 compounds were selected from 146 compounds and tested at $1 \mu \mathrm{M}$ and $10 \mu \mathrm{M}$. The $\%$ remaining was calculated by comparing the amount of compounds at 60 -min incubation or other time points with the amounts of compounds at time $0 \mathrm{~min}$. The half life $\left(\mathrm{t}_{1 / 2}\right)$ was obtained by linear regression of \% remaining over 60 -min or multiple time points. The precision of the experiment and sample analysis in our laboratory is reflected in inter-day comparisons with midazolam (Sigma Chemicals St. Louis MO) as a positive control, which exhibited a stability of $48.4 \%$ remaining, $(\mathrm{n}=175, \mathrm{SD}= \pm 4.83 \%, \% \mathrm{CV}= \pm 9.98 \%)$.

\section{Plasma Protein Binding and S-9 Binding}

Equilibrium dialysis assay was used to measure plasma protein binding and S-9 binding. 29 compounds were selected from 146 compounds for S9 binding study. Tested compounds $(10 \mu \mathrm{M}, \mathrm{v} / \mathrm{v})$ were mixed with mouse liver S9 $(0.5 \mathrm{mg} / \mathrm{mL})$. The mixtures were subjected to equilibrium dialysis versus phosphate buffer saline (PBS) at $37^{\circ} \mathrm{C}$ using HT Dialysis 96 well plate (HT Dialysis LLC, Gales Ferry, CT). Dialysis membranes, with molecular mass cutoff of 12 to $14 \mathrm{~K}$ (HT Dialysis LLC, Gales Ferry, CT), were used and the plates were incubated at $37{ }^{\circ} \mathrm{C}$ for $4 \mathrm{~h}$. Dialysis experiments were done in duplicate. Once the dialysis period was completed, the S-9 and buffer samples were removed and analyzed by HPLC/MS/MS. Plasma protein bindings of 146 compounds were conducted with the same method as the S-9 binding study.

\section{LogP and Polar Surface Area (PSA)}

$\log \mathrm{P}$ and PSA were calculated using Scitegic Pipeline Pilot Version 7.0.1.

\section{In vivo Animal Studies}

\section{Pharmacokinetics Studies}

All mouse experimental procedures were reviewed and approved by the Lexicon Institutional Animal Care and Use Committee (IACUC). Generally, 8-12-week-old C57BL/6 (albino) male mice were used for all pharmacokinetic studies. Animals were housed in micro isolator cages in a tem- perature and light/dark cycle-controlled environment with access to standard chow diet and water ad libitum.

Four mice were used in each study. Compounds were dissolved in $0.1 \%$ Tween 80 (Sigma Chemicals St. Louis $\mathrm{MO}$ ) or other vehicles. Mice received a single intravenous dose of $1 \mathrm{mg} / \mathrm{kg}$. Blood samples were collected from either retro-orbitally or from the saphenous vein using EDTA tubes at $0.08,0.25,0.5,1,2,4,6$ and $24 \mathrm{~h}$. Plasma was separated by centrifugation at $5000 \mathrm{rpm}$ for $5 \mathrm{~min}$ and stored at $-20^{\circ} \mathrm{C}$ until analysis. Samples were analyzed by LC/MS/MS.

\section{Sample Analysis by LC/MS}

The concentration of each compound in the blood plasma from the PK studies was determined by LC/MS/MS. Prior to analysis, the plasma samples were protein precipitated with ten volumes of acetonitrile:water (80:20) containing $1 \mathrm{ug} / \mathrm{mL}$ verapamil (Sigma Chemicals St. Louis MO.) as an internal standard. Upon addition of the acetonitrile/water mixture, the plasma was vortexed for 3 minutes and centrifuged for 10 minutes at $14000 \mathrm{rpm}$ with a Beckman Coulter Micro II centrifuge. Calibration curves of the analytes in blood plasma were prepared over the range $1.3 \mathrm{ng} / \mathrm{mL}$ to $10,000 \mathrm{ng} / \mathrm{mL}$ and were protein precipitated as described above. The calibration curves for the analytes were linear over the range of the measured unknown concentrations. The precison intra-and inter-day of analytes were satisfactory with $\mathrm{CV}$ value less than $15 \%$. The accuracy of the assay obtained with quality control samples containing 1.3, 46.3 and $1670 \mathrm{ng} / \mathrm{mL}$ analytes were between $85 \%$ and $115 \%$. The liquid chromatography system consisted of a Thermo Electron MS Pump and a CTC HTS autosampler. The chromatography column was an Agilent SB C8, $2.1 \mathrm{~mm} \times 15 \mathrm{~mm}, 3.5 \mu \mathrm{m}$ particle size. The mobile phases used in the gradient chromatography methods were: A; water with $0.1 \%$ formic acid: $\mathrm{B}$; acetonitrile with $0.1 \%$ formic acid. The gradient had the following time profile: 0 minutes, $95 \% \mathrm{~A} ; 0.5$ minutes, $95 \% \mathrm{~A} ; 1.0$ minutes, $5.0 \%$ A; 2 minutes, $5.0 \%$ A; 2.1 minutes $95 \% \mathrm{~A}$; 2.5 minutes, $95 \% \mathrm{~A}$. The chromatographic flow rate was 0.5 $\mathrm{mL} /$ minute and an injection volume was $10 \mu \mathrm{L}$. Mass spectrometry was performed with a Thermo Electron TSQ Quantum Ultra AM or an Applied Biosystems 3000 mass spectrometer. The analyte and internal standard peaks were monitored with single reaction monitoring mode (SRM). Positive mode electrospray ionization was used for most compounds; however, negative mode electrospray and negative mode atomospheric pressure ionization were used for some of the compounds in this study.

The analytical method to determine the levels of compound in the metabolic stability and protein binding studies has similar extraction and chromatography methods to those used for plasma analysis in the PK studies. The mass spectrometry methods generally involved single ion monitoring (SIM) with some compounds requiring SRM methods when more signal:noise was necessary.

\section{Calculations of In Vitro Intrinsic Clearance $\left(\mathrm{CL}_{\mathrm{int}}\right.$, in vitro $)$ and Predicted $\mathbf{C L}$ in vitro}

The in vitro intrinsic clearance $\left(\mathrm{CL}_{\mathrm{int}}\right.$, in vitro $)$ of tested compounds was calculated based on substrate disappearance rate in $\mathrm{S} 9$ as follow: 
$\mathrm{CL}_{\text {int, } \text { in vitro }}=\frac{0.693}{\text { In vitro } \mathrm{t}_{1 / 2}} \times \frac{\mathrm{mL} \text { incubation }}{\mathrm{mg} \text { liver } \mathrm{S}-9} \times \frac{85 \mathrm{mg} \text { liver } \mathrm{S}-9}{\mathrm{~g} \text { liver }} \times \frac{50 \mathrm{~g} \text { liver }}{\mathrm{kg} \mathrm{b.w} .}$

$\mathrm{CL}_{\text {in vitro }}$ was predicted based on well-stirred model or parallel tube model with some modifications as shown in Table 1.

Percentages of prediction were calculated from the plot between the predicted and observed CL in linear scale. On this plot, dot-lines indicated 2-fold error on the perfect clearance prediction, a solid line. Compounds falling inside the 2 fold error were accepted as good predicted compounds.

\section{Data Analysis and Statistics}

WinNonlin Professional, version 5.0 (Pharsight Corporation, USA) was used to estimate Pharmacokinetic parameters of tested compounds. Clearance (CL) and volume of distribution at the steady state (Vss) were calculated according to non-compartmental methods. Statistics analysis was performed using nonparametric statistic test (GraphPad Prism ${ }^{\circledR}$, version 4.0). Spearman coefficient factor $r$ (r) was used to represent correlation.

\section{RESULTS}

The physicochemical properties and in vitro and in vivo ADME parameters, including plasma protein binding, metabolic stability using $10 \mu \mathrm{M}$ substrate concentration and mouse in vivo PK data of 146 compounds of diverse chemotypes are summarized in Table 2. PSA values were in the range of 45 to 159 . LogP values varied between -1.9 to 6.4 . The values of $f_{u}$, plasma ranged from 0.001 to 1 . The metabolic stability of these compounds spanned a wide range from 44.7 to $99.9 \%$ stable. In vivo $\mathrm{CL}$ was in the range of 0.79 to $89.00 \mathrm{~mL} / \mathrm{min} / \mathrm{kg}$ and Vss varied between 0.19 to $40.9 \mathrm{~L} / \mathrm{kg}$.

The possible relationship between in vivo CL and predicted $\mathrm{CL}_{\text {in vitro }}$ was examined using both the well-stirred model (model A) and parallel-tube model (model E) are presented in Fig. (1) and Tables 2 and 3. For all 146 compounds, the percentage of compounds falling inside the 2fold error was similar for the well-stirred and parallel-tube models, (i.e. $45 \%$ ). Using either the well-stirred model or parallel-tube model, approximately $27 \%$ and $29 \%$ of the compounds were over and under predicted, respectively. A nonparametric statistic test was used to estimate the correlation between in vivo $\mathrm{CL}$ and predicted $\mathrm{CL}_{\text {in vitro }}$ due to the variability in the data. Spearman $r$ was 0.26 for both the well-stirred and parallel tube models. These results indicated no significant correlation between predicted $\mathrm{CL}_{\text {in vitro }}$ and in vivo CL. Incorporation of the plasma unbound fraction (model B and model F) did not improve the relationship, with both models showing approximately $14 \%$ agreement between in vivo $\mathrm{CL}$ and pre-dicted $\mathrm{CL}_{\text {in vitro }}$. Spearman $\mathrm{r}$ for both models was 0.04 (Table 2 and Table 3 ).

The effect of different substrate concentrations and sampling time points was also investigated to see if it would improve the correlation between in vivo $\mathrm{CL}$ and predicted $\mathrm{CL}_{\text {in }}$ vitro. Using substrate concentrations of either $1 \mu \mathrm{M}$ or $10 \mu \mathrm{M}$ did not improve the correlation showing only $46 \%$ and $26 \%$ agreement, respectively. Spearman $\mathrm{r}$ for $1 \mu \mathrm{M}$ and $10 \mu \mathrm{M}$ substrates were -0.03 and -0.10 , respectively (Fig. 2 and

Table 1. Models Used to Calculate Predicted $\mathbf{C L}_{\text {in vitro }}$

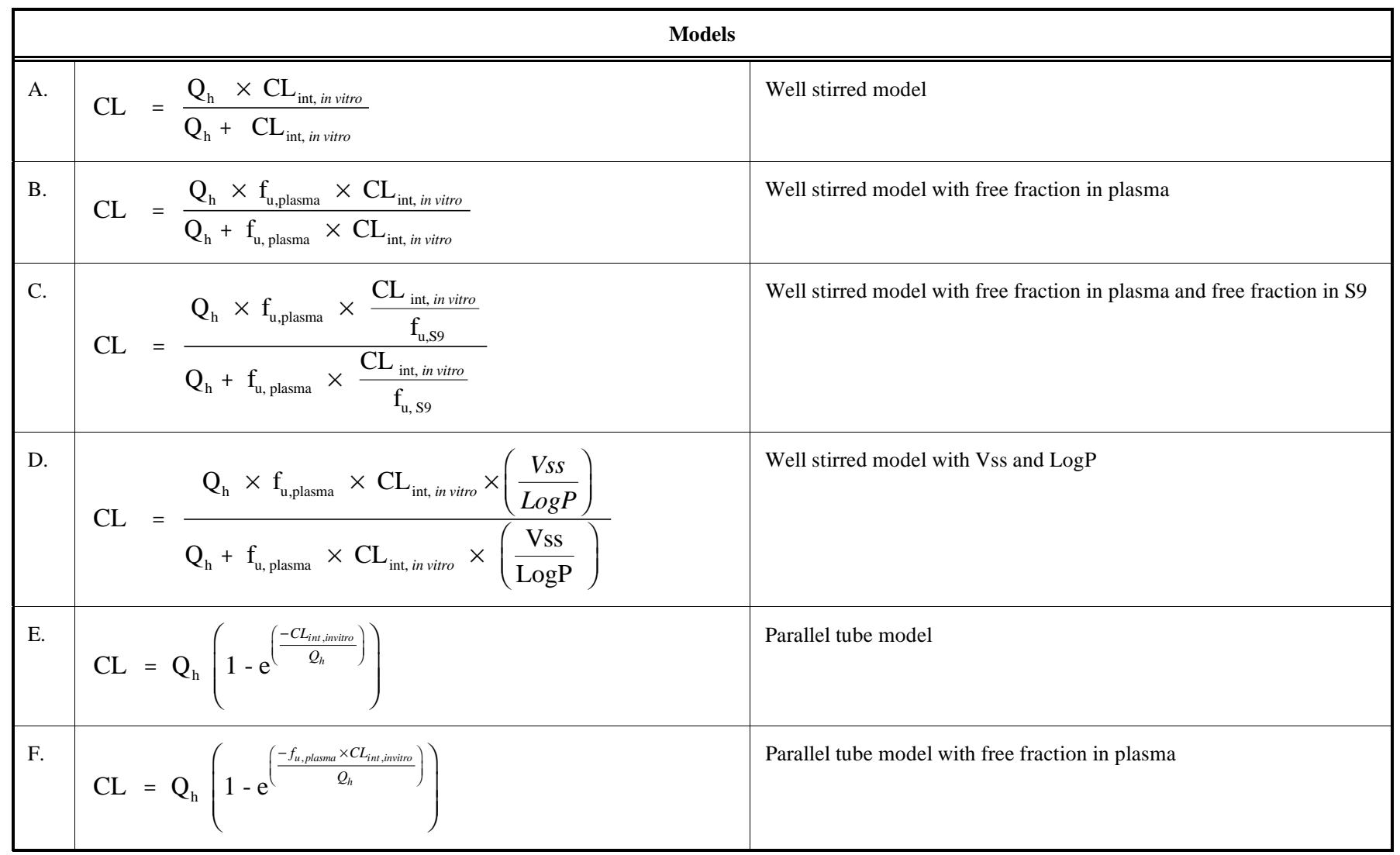

Note: $\mathrm{f}_{\mathrm{u}, \text { plasma }}$ is the free fraction in plasma, $\mathrm{f}_{\mathrm{u}, \mathrm{S} 9}$ is the free fraction in $\mathrm{S} 9$, Vss is the volume distribution at the steady state and $\mathrm{Q}_{\mathrm{h}}$ is the hepatic blood flow of $90 \mathrm{~mL} / \mathrm{min} / \mathrm{kg}$. 
Table 2. Values for In Vivo Clearance, Fraction Unbound in Plasma, Polar Surface Area, logP, Volume of Distribution, \% AUCextrapolated, \% Remaining in Metabolic Stability Study, Intrinsic Clearance and Predicted CL in vitro of 146 Compounds Using Model A, B, E and F

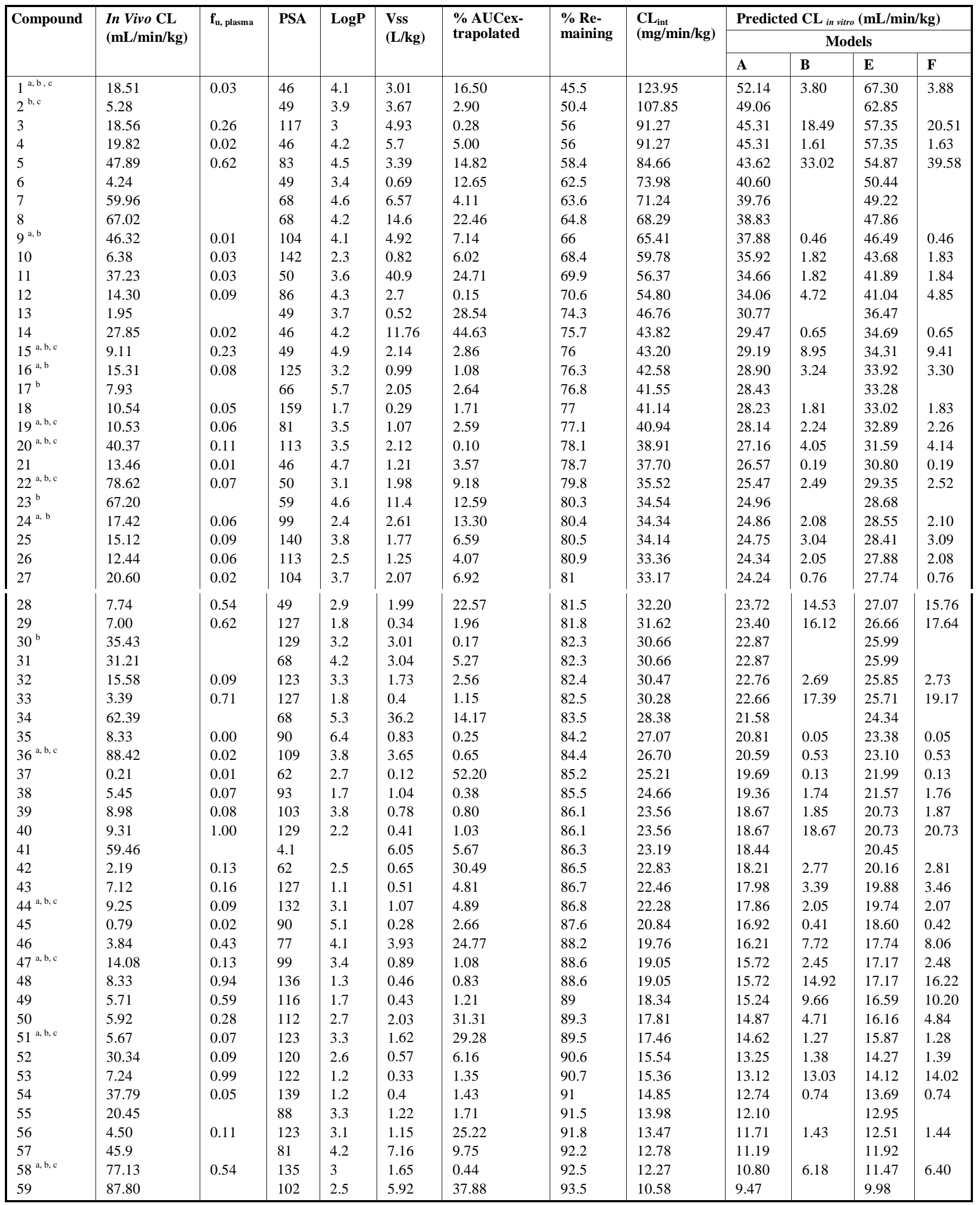


(Table 2). Contd....

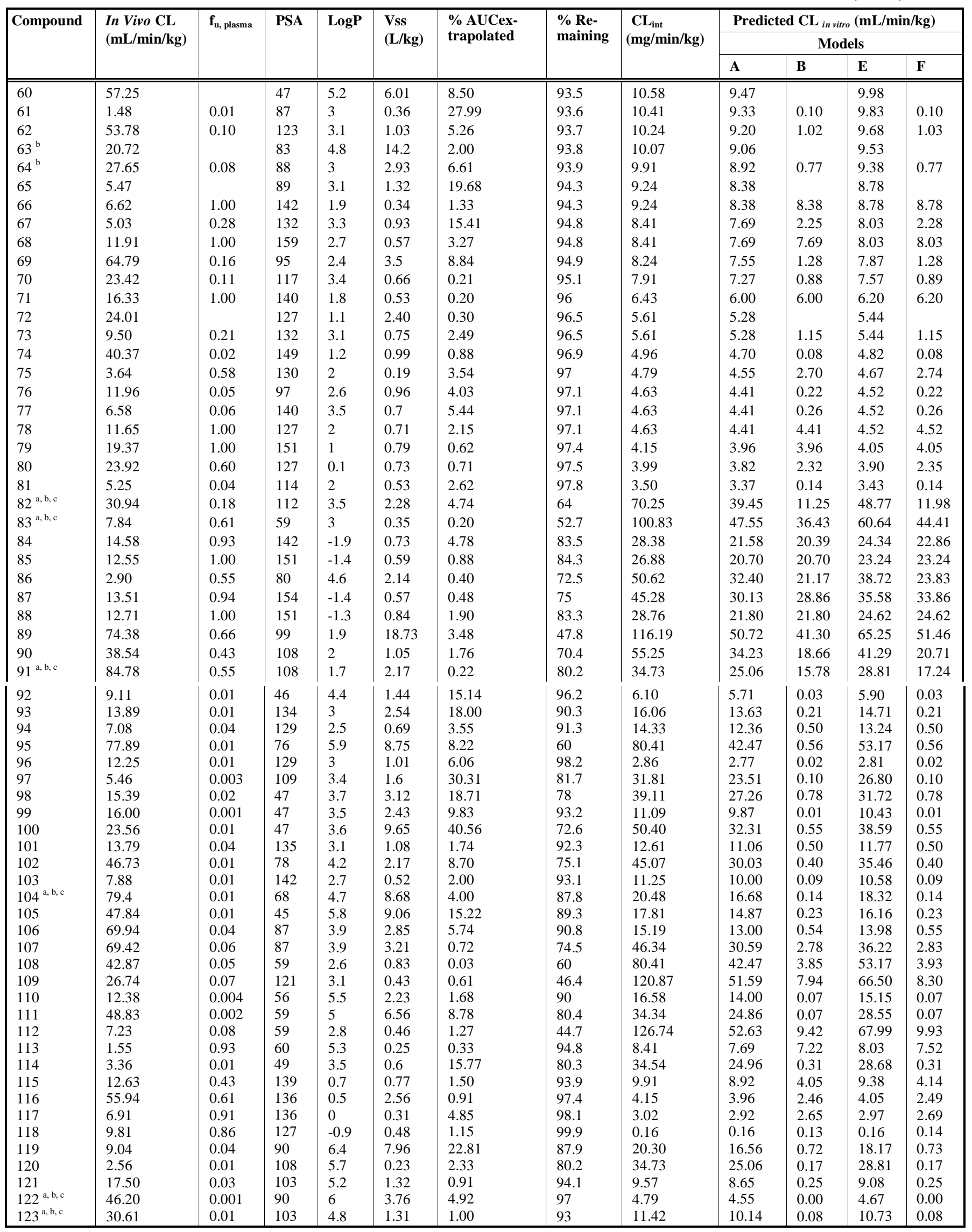


(Table 2). Contd.....

\begin{tabular}{|c|c|c|c|c|c|c|c|c|c|c|c|c|}
\hline \multirow[t]{3}{*}{ Compound } & \multirow{3}{*}{$\begin{array}{l}\text { In Vivo CL } \\
(\mathrm{mL} / \mathrm{min} / \mathrm{kg})\end{array}$} & \multirow[t]{3}{*}{$\mathbf{f}_{\mathrm{u}, \text { plasma }}$} & \multirow[t]{3}{*}{ PSA } & \multirow[t]{3}{*}{$\log P$} & \multirow{3}{*}{$\begin{array}{l}\text { Vss } \\
\text { (L/kg) }\end{array}$} & \multirow{3}{*}{$\begin{array}{l}\text { \% AUCex- } \\
\text { trapolated }\end{array}$} & \multirow{3}{*}{$\begin{array}{l}\% \text { Re- } \\
\text { maining }\end{array}$} & \multirow{3}{*}{$\begin{array}{l}\mathrm{CL}_{\text {int }} \\
(\mathrm{mg} / \mathrm{min} / \mathrm{kg})\end{array}$} & \multirow{2}{*}{\multicolumn{4}{|c|}{$\begin{array}{c}\text { Predicted CL }{ }_{\text {in vitro }}(\mathrm{mL} / \mathrm{min} / \mathrm{kg}) \\
\text { Models }\end{array}$}} \\
\hline & & & & & & & & & & & & \\
\hline & & & & & & & & & A & B & $\mathbf{E}$ & $\mathbf{F}$ \\
\hline 124 & 39.00 & 0.03 & 103 & 5.4 & 6.58 & 10.10 & 75 & 45.28 & 30.13 & 1.47 & 35.58 & 1.48 \\
\hline 125 & 7.58 & 0.02 & 69 & 5.3 & 1.05 & 11.39 & 94 & 9.74 & 8.79 & 0.16 & 9.23 & 0.16 \\
\hline 126 & 19.00 & 0.02 & 82 & 4.1 & 1.03 & 3.42 & 94 & 9.74 & 8.79 & 0.20 & 9.23 & 0.20 \\
\hline $127^{\mathrm{a}, \mathrm{b}, \mathrm{c}}$ & 14.00 & 0.05 & 85 & 6.4 & 6.40 & 9.35 & 91 & 14.85 & 12.74 & 0.74 & 13.69 & 0.74 \\
\hline $128^{\mathrm{a}, \mathrm{b}, \mathrm{c}}$ & 6.00 & 0.08 & 90 & 6.0 & 1.70 & 1.25 & 89 & 18.34 & 15.24 & 1.44 & 16.59 & 1.46 \\
\hline $129^{a, b, c}$ & 9.70 & 0.004 & 101 & 5.5 & 0.50 & 0.81 & 94 & 9.74 & 8.79 & 0.04 & 9.23 & 0.04 \\
\hline 130 & 15.10 & 0.01 & 99 & 4.0 & 0.45 & 1.48 & 88 & 20.12 & 16.45 & 0.20 & 18.03 & 0.20 \\
\hline 131 & 2.70 & 0.03 & 86 & 5.1 & 0.28 & 0.20 & 97 & 4.79 & 4.55 & 0.14 & 4.67 & 0.14 \\
\hline 132 & 16.20 & 0.01 & 121 & 4.7 & 0.49 & 0.88 & 85 & 25.58 & 19.92 & 0.28 & 22.27 & 0.28 \\
\hline 133 & 16.20 & 0.02 & 134 & 3.5 & 1.56 & 2.57 & 85 & 25.58 & 19.92 & 0.38 & 22.27 & 0.38 \\
\hline $134^{\mathrm{a}, \mathrm{b}, \mathrm{c}}$ & 5.20 & 0.06 & 131 & 6.4 & 0.39 & 3.42 & 44 & 129.23 & 53.05 & 6.59 & 68.59 & 6.83 \\
\hline 135 & 13.60 & 0.06 & 76 & 5.8 & 1.32 & 5.07 & 92.2 & 12.78 & 11.19 & 0.79 & 11.92 & 0.79 \\
\hline $136^{\mathrm{a}, \mathrm{b}, \mathrm{c}}$ & 84.58 & 0.06 & 96 & 2.5 & 1.95 & 0.26 & 66.5 & 64.22 & 37.48 & 3.87 & 45.91 & 3.96 \\
\hline $137^{\mathrm{a}, \mathrm{b}, \mathrm{c}}$ & 75.10 & 0.04 & 114 & 2.6 & 1.92 & 0.23 & 70.1 & 55.92 & 34.49 & 2.34 & 41.65 & 2.37 \\
\hline 138 & 76.80 & 0.02 & 135 & 2.6 & 7.26 & 6.45 & 69 & 58.41 & 35.42 & 1.10 & 42.97 & 1.10 \\
\hline 139 & 75.00 & 0.04 & 120 & 4.1 & 1.97 & 7.28 & 65.2 & 67.32 & 38.51 & 2.42 & 47.40 & 2.46 \\
\hline 140 & 78.15 & 0.12 & 99 & 2.6 & 7.21 & 4.00 & 53 & 99.93 & 47.35 & 10.81 & 60.35 & 11.49 \\
\hline 141 & 74.38 & 0.66 & 56 & 4.1 & 18.73 & 3.48 & 47.8 & 116.19 & 50.72 & 41.30 & 65.25 & 51.46 \\
\hline 142 & 72.09 & 0.31 & 98 & 3.2 & 0.58 & 2.16 & 59.3 & 82.25 & 42.98 & 19.72 & 53.92 & 22.02 \\
\hline $143^{\mathrm{a}, \mathrm{b}, \mathrm{c}}$ & 73.00 & 0.004 & 59 & 6.0 & 9.50 & 5.49 & 74.3 & 46.76 & 30.77 & 0.19 & 36.47 & 0.19 \\
\hline $144^{\mathrm{a}, \mathrm{b}, \mathrm{c}}$ & 82.00 & 0.19 & 81 & 3.5 & 10.20 & 10.28 & 60.4 & 79.36 & 42.17 & 12.97 & 52.74 & 13.95 \\
\hline $145^{\mathrm{a}, \mathrm{b}, \mathrm{c}}$ & 87.00 & 0.04 & 68 & 4.6 & 13.10 & 12.67 & 75.2 & 44.86 & 29.94 & 1.89 & 35.33 & 1.91 \\
\hline $146^{\mathrm{a}, \mathrm{b}, \mathrm{c}}$ & 89.00 & 0.02 & 56 & 4.1 & 9.60 & 4.08 & 66.7 & 63.74 & 37.32 & 1.07 & 45.68 & 1.08 \\
\hline
\end{tabular}

Note: a, compounds used in S9 binding study; b, compounds used in different substrate concentrations in metabolic stability assay; c, compounds used in multiple time points study in metabolic stability assay.

A

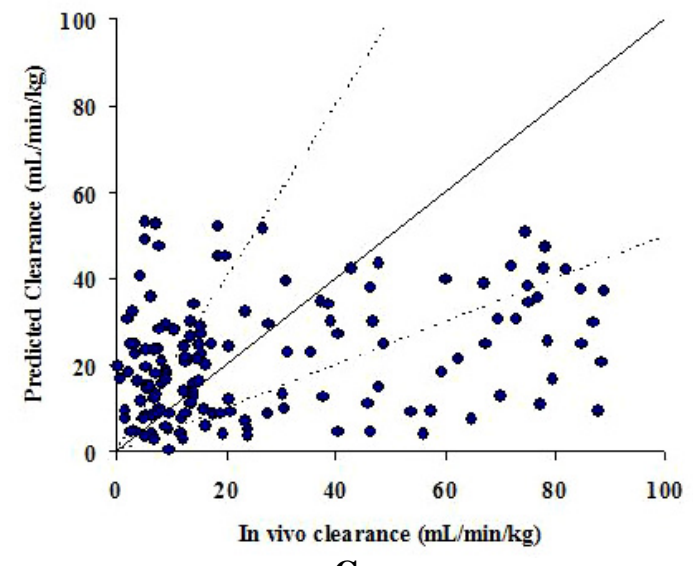

C

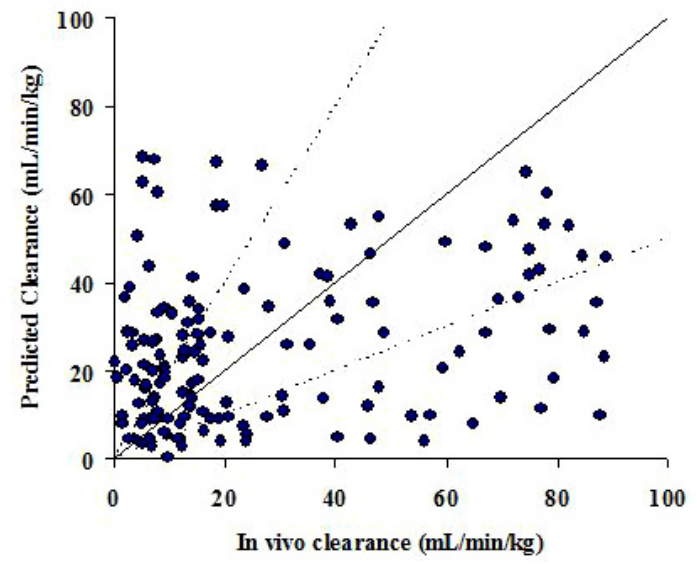

B

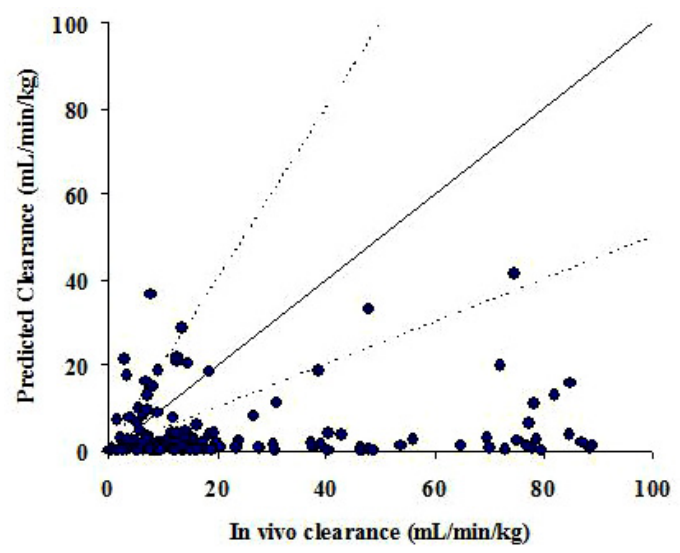

D

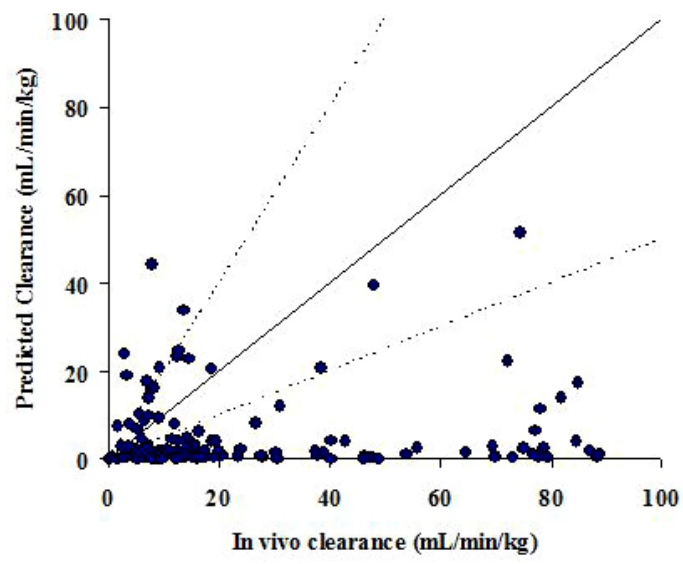

Fig. (1). Plots between in vivo $\mathrm{CL}$ and predicted CL from mouse $\mathrm{S} 9(\mathrm{~N}=146)$. A, Model A. B, Model B. C, Model E. D, Model F. Solid line represents lines of unity, and the area between the dot-lines represents an area within 2-fold error. 
Table 3. Percentages of Compounds Falling into Good Prediction, Under Prediction and Over Prediction and $\mathbf{r}$ Values Using Model A, B, E and F (N=146)

\begin{tabular}{|c|c|c|c|c|}
\hline Model & \multicolumn{3}{|c|}{$\%$ of Compounds } & $\mathbf{r}$ \\
\hline No binding (Model A) & 44.52 & 28.77 & 26.71 & 0.26 \\
\hline Including $\mathrm{f}_{\mathrm{u} \text {, plasma }}($ Model $\mathrm{B})$ & 13.95 & 80.62 & 5.43 & 0.04 \\
\hline Including $\mathrm{f}_{\mathrm{u} \text {, plasma }}($ Model $\mathrm{F})$ & 16.28 & 76.74 & 6.98 & 0.04 \\
\hline
\end{tabular}

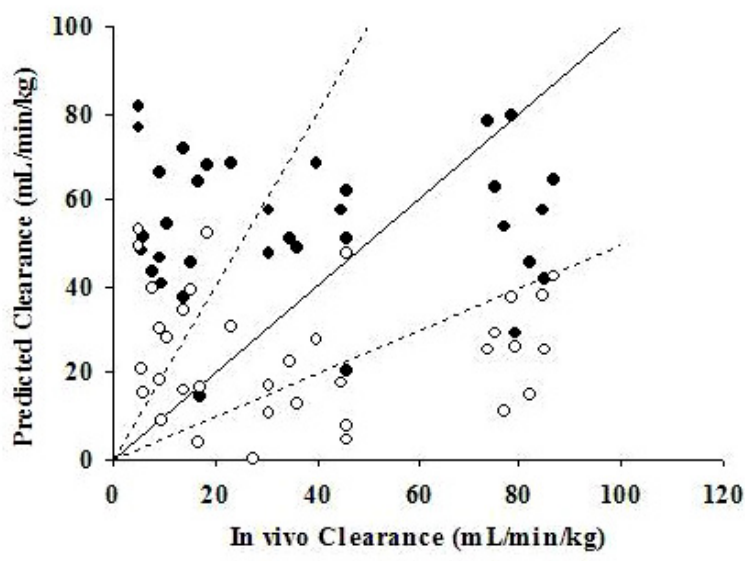

Fig. (2). Plots between in vivo $\mathrm{CL}$ and predicted $\mathrm{CL}_{\text {in vitro }}$ from mouse $\mathrm{S} 9$ calculated from model $\mathrm{A}(\mathrm{N}=27)$. $\circ$ represents $10 \mu \mathrm{M}$ substrate concentration and $\bullet$ represents $1 \mu \mathrm{M}$ substrate concentration. Solid line represents lines of unity, and the area between the dot-lines represents an area within 2-fold error.

Table 4). The results also showed that calculation of $t_{1 / 2}$ using either single or multiple time points produced comparable estimates of predicted $\mathrm{CL}_{\text {in vitro }}$ (Fig. 3). To further analyze the data, a binary classification was applied to $146 \mathrm{com}-$ pounds. The classifications were based on the extent of metabolic stability (i.e moderate $30-70 \%$ and high $>70 \%$ ) as shown in Table 5. Compounds with in vitro metabolic stability $<30 \%$ were not included in this analysis, since they are rarely progressed to in vivo PK studies because of the high degree of metabolism and therefore have limited PK data available. The plots between in vivo $\mathrm{CL}$ and predicted $\mathrm{CL}_{\text {in }}$ vitro calculated from well stirred model (model A) are presented in Fig. (4). For 27 compounds, with moderate metabolic stability (30\%-70\% remaining), there was little apparent correlation between in vivo $\mathrm{CL}$ and predicted $\mathrm{CL}_{\text {in vitro }}$.
The percentage of agreement and Spearman $\mathrm{r}$ were $\sim 56 \%$ and -0.39 , respectively. A similar finding was observed for the 119 compounds with high metabolic stability (>70\% remaining). The percentage of agreement and Spearman $r$ were $\sim 43 \%$ and 0.17 , respectively.

Incorporation of the extent of binding to the mouse liver S-9 was determined for 29 compounds. The extent of S9 binding ranged from $6.5 \%$ to $97.3 \%$. Well stirred model with plasma and S9 binding (Model C) was used to calculate predicted $\mathrm{CL}_{\text {in vitro }}$. The result showed that correction of the $\mathrm{CL}_{\text {in vitro }}$ for the extent of $\mathrm{S} 9$ binding did not improve the correlation. In addition, correction for both plasma and S-9 binding together also failed to improve the relationship between in vivo $\mathrm{CL}$ and predicted $\mathrm{CL}_{\text {in vitro }}$ (Fig. 5). The percentage of compounds falling inside the 2 fold error and Spearman $\mathrm{r}$ were $28 \%$ and 0.06 , respectively (Table 6).

In general, over predicted compounds had lower Vss $(1.35 \pm 1.35 \mathrm{~L} / \mathrm{kg})$, lower in vivo $\mathrm{CL}(6.88 \pm 4.76$ $\mathrm{mL} / \mathrm{min} / \mathrm{kg})$, lower plasma protein binding $(74.77 \% \pm$ $30.61 \%)$, lower PSA $(90.46 \pm 33.48)$ and had high metabolic stability (i.e. $\%$ remaining $76.5 \% \pm 14.6 \%$ ) compared with well predicted and under predicted compounds (Table 7). Inclusion of Vss and $\log \mathrm{P}$ into the well-stirred model (model D) improved the agreement between predicted $\mathrm{CL}_{\text {in vitro }}$ and in vivo CL to $59 \%$ for over predicted compounds and to $19 \%$ for under predicted compounds, whereas, inclusion of Vss and $\log \mathrm{P}$ worsened the agreement by $57 \%$ for well predicted compounds (Fig. 6). Under predicted compounds were generally metabolically stable ( $\sim 89 \%$ remaining) and had clearance values of $\sim 50 \mathrm{~mL} / \mathrm{kg} / \mathrm{min}$.

In an attempt to improve the relationship between predicted $\mathrm{CL}_{\text {in vitro }}$ and in vivo $\mathrm{CL}$, compounds were classified into 3 groups based on in vivo $\mathrm{CL}$ values (low: < 30 $\mathrm{mL} / \mathrm{min} / \mathrm{kg}$, medium: 30-70 $\mathrm{mL} / \mathrm{min} / \mathrm{kg}$ and high: $>70$

Table 4. Percentages of Compounds Falling into Good Prediction, Under Prediction and Over Prediction and r Values of 35 Compounds Using $1 \mu \mathrm{M}$ or $10 \mu \mathrm{M}$ Substrate Concentrations in Metabolic Stability Study. Predicted CL was Calculated Based on Model A

\begin{tabular}{|c|c|c|c|c|}
\hline \multirow{2}{*}{ Substrate Concentration $(\mu \mathrm{M})$} & \multicolumn{3}{|c|}{ \% of Compounds } & \multirow{2}{*}{ r } \\
\cline { 2 - 5 } & Good Prediction & Under Prediction & 42.9 & -0.03 \\
\hline \hline $1 \mu \mathrm{M}$ & 45.7 & 11.4 & 25.7 & -0.10 \\
$10 \mu \mathrm{M}$ & 25.7 & 48.6 & \multicolumn{2}{|c|}{ Over Prediction } \\
\hline
\end{tabular}




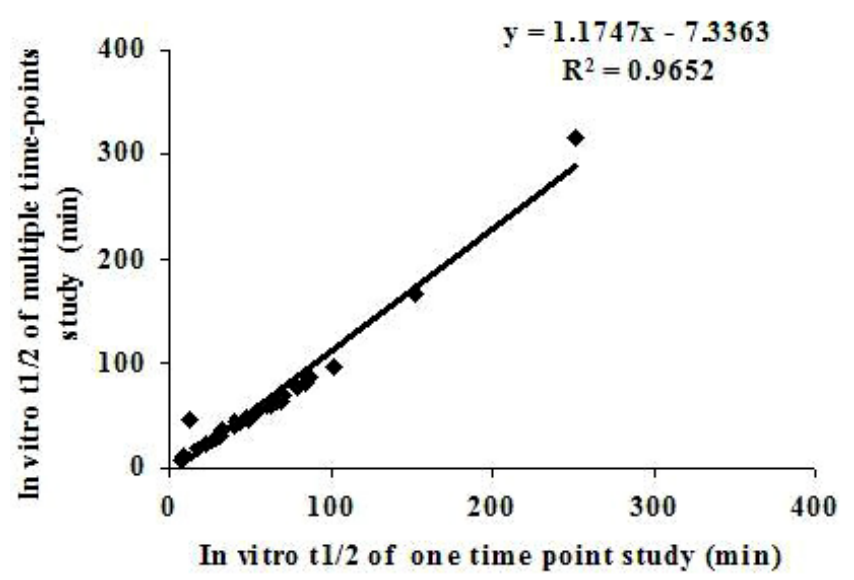

Fig. (3). Plots between in vitro $t_{1 / 2}$ of one time point study and in vitro $\mathrm{t}_{1 / 2}$ of multiple time-points study in metabolic stability assay using $1 \mu \mathrm{M}$ substrate concentration $(\mathrm{N}=27)$. Solid line represent the linear regression line with $\mathrm{y}=1.1747 \mathrm{x}-7.3363$ and $\mathrm{R}^{2}=$ 0.9652 .

$\mathrm{mL} / \mathrm{min} / \mathrm{kg}$ ) [9, 10]. The percentage agreement for compounds with $\mathrm{CL}<30 \mathrm{~mL} / \mathrm{min} / \mathrm{kg}, \mathrm{CL}$ values of $30-70$ $\mathrm{mL} / \mathrm{min} / \mathrm{kg}$, and CL $>70 \mathrm{~mL} / \mathrm{min} / \mathrm{kg}$ was $54 \%, 31 \%$ and 24 $\%$ respectively. Spearman $\mathrm{r}$ values for compounds with low, medium and high CL were $0.011,-0.039$ and -0.512 , respectively. These results showed that there was poor correlation between in vivo $\mathrm{CL}$ and predicted $\mathrm{CL}_{\text {in vitro }}$ for all groups, although the low CL group showed a slightly better prediction of CL compared with moderate and high CL groups. Most of compounds in the high CL group showed under prediction of CL (Fig. 7, Table 8).

\section{DISCUSSION}

Earlier published studies have suggested that intrinsic CL obtained from in vitro metabolic studies can be used to predict in vivo CL $[8,11,12]$. The good correlation appears to have been observed generally with extensively metabolized compounds for which hepatic clearance was the major clearance mechanism. In general industry practice, compounds showing high metabolic instability ( $<30 \%$ remaining) are usually not advanced into in vivo study. We have therefore examined whether the commonly used high throughput metabolic stability assay can provide a robust and reliable estimation of in vivo CL.

In this study, we have investigated the correlation between in vivo $\mathrm{CL}$ and predicted $\mathrm{CL}_{\text {in vitro }}$ for 146 structurally diverse compounds. The metabolic stability assay used to determine $\mathrm{CL}_{\text {in vitro }}$ was performed with mouse liver $\mathrm{S} 9$ and $\mathrm{CL}_{\text {in }}$ vitro was calculated using well-stirred or parallel tube

Table 5. Classification of 146 Compounds Based on Metabolic Stability Data. Percentages of Compounds Falling into Good Prediction, Under Prediction and over Prediction and r Values Using Model A

\begin{tabular}{|c|c|c|c|c|}
\hline \multirow[t]{2}{*}{ Metabolic Stability } & \multicolumn{3}{|c|}{$\%$ of Compounds } & \multirow[t]{2}{*}{$\mathbf{r}$} \\
\hline & Good Prediction & Under Prediction & Over Prediction & \\
\hline $30 \%-70 \%(\mathrm{~N}=27)$ & 55.6 & 11.1 & 33.3 & -0.39 \\
\hline$>70 \%(\mathrm{~N}=119)$ & 42.9 & 31.9 & 25.2 & 0.17 \\
\hline
\end{tabular}

A

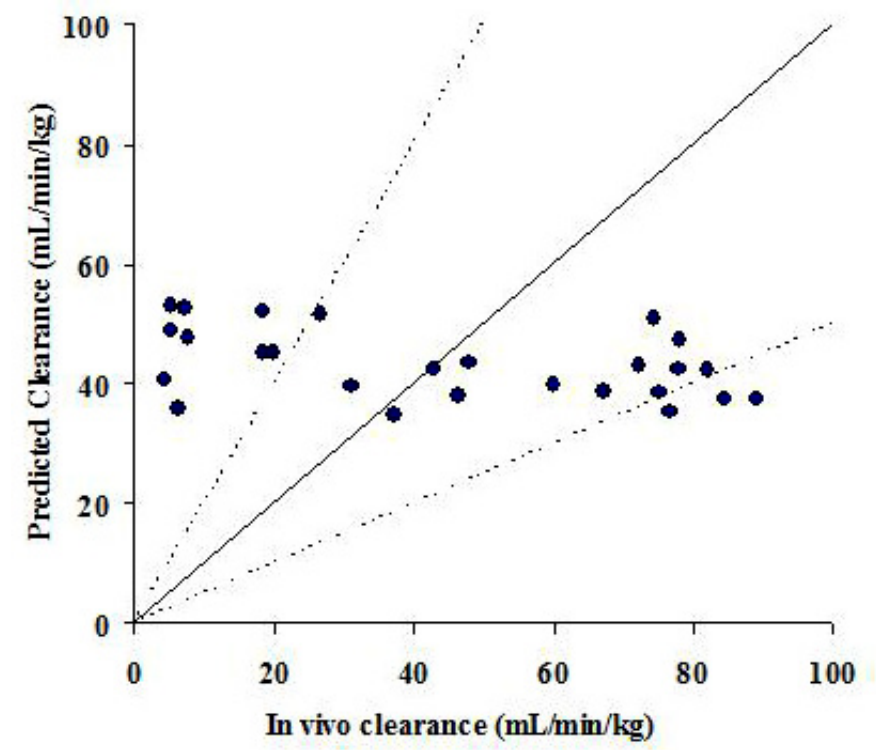

B

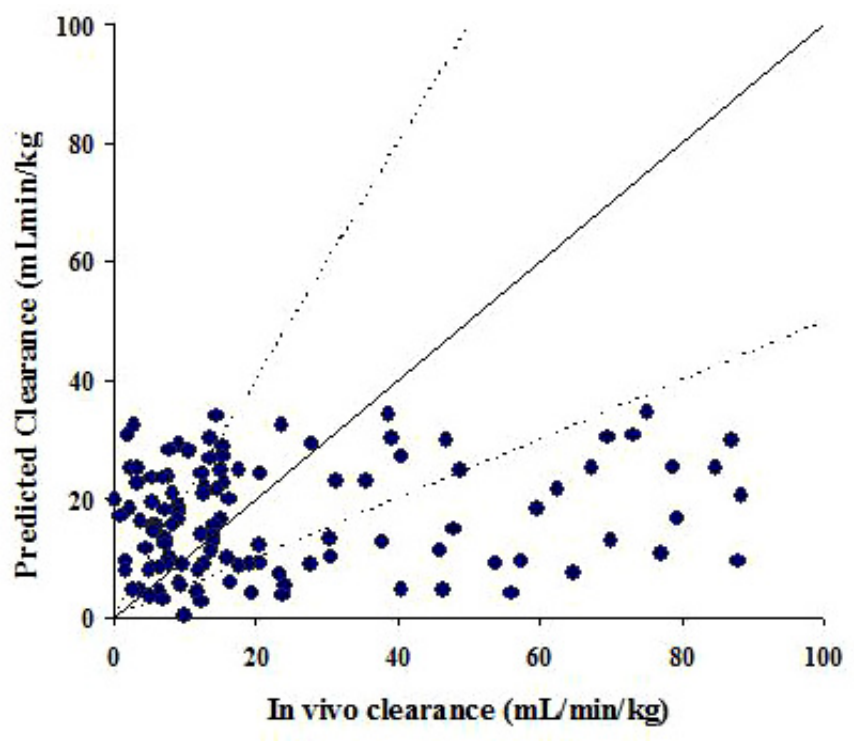

Fig. (4). Plots between in vivo $\mathrm{CL}$ and predicted $\mathrm{CL}_{\text {in vitro }}$ from mouse $\mathrm{S} 9$ calculated from model $\mathrm{A}$. A, compounds with moderate metabolic stability $(30 \%-70 \%)$. B, compounds with high metabolic stability $(>70 \%)$. Solid line represents lines of unity, and the area between the dotlines represents an area within 2-fold error. 


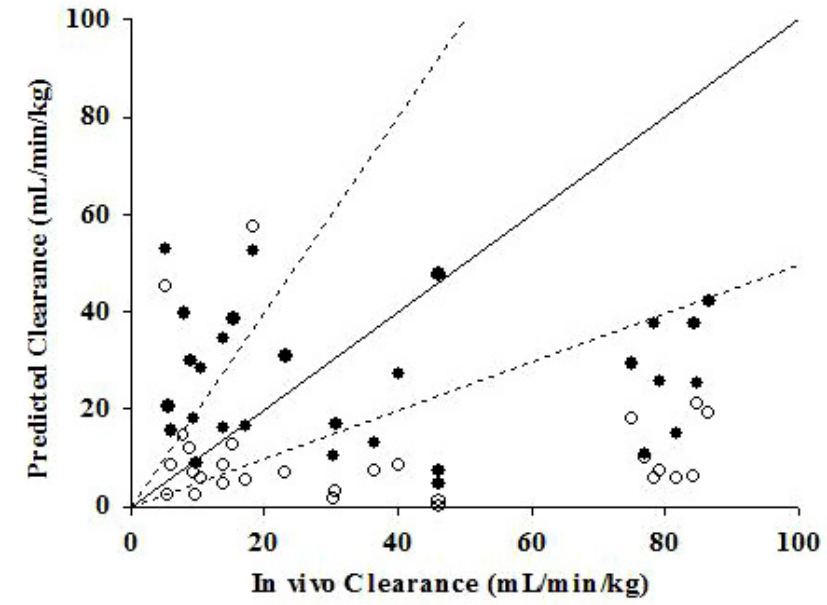

Fig. (5). Plots between in vivo $\mathrm{CL}$ and predicted $\mathrm{CL}_{\text {in vitro }}$ from mouse S9 calculated from well-stirred model $(\mathrm{N}=29)$. $\bullet$ represents model A and $\circ$ represents model C. Solid line represents lines of unity, and the area between the dot-lines represents an area within 2-fold error.

models with three different iterations: 1) no binding parameters (Table 1, model A and E); 2) incorporating only plasma binding (Table $\mathbf{1}$, model $\mathrm{B}$ and $\mathrm{F}$ ); 3 ) incorporating both plasma and S9 bindings (Table 1, equation $\mathrm{C}$ ). The results of our studies have shown that compounds with moderate (30\%-70\% remaining) and high (>70\% remaining) metabolic stability showed poor correlation between in vivo $\mathrm{CL}$ and predicted $\mathrm{CL}_{\text {in }}$ vitro when used either well stirred model (model A) or parallel tubed model (model E). Incorporating plasma protein binding (model $\mathrm{B}$ and $\mathrm{F}$ ) did not improve the correlation between in vivo $\mathrm{CL}$ and predicted $\mathrm{CL}_{\text {in vitro }}$, which is consistent with previous studies $[3,7,8,13,14]$.
The inclusion of both plasma protein binding and microsome binding has been suggested to be important in liver models [8,15]. However, our study showed that including both plasma binding and S9 binding did not improve a correlation between in vivo $\mathrm{CL}$ and predicted $\mathrm{CL}_{\text {in vitro }}$.

The use of the disappearance method to determine $\mathrm{CL}_{\text {int }}$ is based on the concept that $\mathrm{CL}_{\text {int }}$ is close to $\mathrm{V}_{\max } / \mathrm{K}_{\mathrm{m}}$ when substrate concentrations are $\ll \mathrm{K}_{\mathrm{m}}$, namely under linear condition. In addition to substrate concentrations, enzyme concentrations and incubation time are also important for linearity. In our study, we have used $10 \mu \mathrm{M}$ substrate concentrations, mouse liver S-9 concentration of $0.45 \mathrm{mg} / \mathrm{mL}$ and a $60 \mathrm{~min}$ incubation time. This method is commonly used in the industry for the conduct of high throughput metabolic stability studies. Substrate and enzyme concentrations used in previous studies varied between $0.5 \mu \mathrm{M}$ and 1 $\mu \mathrm{M}$ substrates and ranged from $0.2 \mathrm{mg}$ to $10 \mathrm{mg}$ microsomal protein/mL, respectively $[8,11,16]$. Although, our substrate concentration was slightly higher than has been used in some other studies, studies in which we have used a substrate concentration of $1 \mu \mathrm{M}$ or with multiple time points showed insignificant improvement in the relationship between in vivo $\mathrm{CL}$ and predicted $\mathrm{CL}_{\text {in vitro }}$ (Fig. 3 and Table 4 ).

$\mathrm{CL}_{\text {in vitro }}$ corrected with Vss and $\log \mathrm{P}$ (model D) could improve the prediction of $\mathrm{CL}_{\text {in vitro }}$ for over predicted compound and under predicted compound. But, for well predicted compounds, using Vss and LogP showed poorer prediction of CL than without using Vss and $\log P$ (model A). However, this model requires in vivo Vss data, and thus this approach would not be applicable for early screening approach and defeat the purpose of using in vitro data to predict in vivo CL.

The use of empirical scaling factor (SF) to improve the correlation between in vitro and in vivo data was used in the study of Ito and Houston [12]. The empirical SF was deter-

Table 6. Percentages of Compounds Falling into Good Prediction, Under Prediction and Over Prediction and $\mathbf{r}$ Values Using Model A, B, and C (N=29)

\begin{tabular}{|l|c|c|c|c|}
\hline \multirow{2}{*}{ Model } & \multicolumn{3}{|c|}{ \% of Compounds } & \multirow{2}{*}{ r } \\
\cline { 2 - 5 } & Good Prediction & Under Prediction & Over Prediction \\
\hline \hline Well-stirred model & & & & \\
No binding (Model A) & 27.6 & 44.8 & 24.1 & -0.07 \\
Including $\mathrm{f}_{\mathrm{u}, \text { plasma }}($ Model B) & 20.7 & 79.3 & - & 0.24 \\
Including $\mathrm{f}_{\mathrm{u}, \text { plasma }}$ and $\mathrm{f}_{\mathrm{u}, \mathrm{s} 9}$ (Model C) & 27.6 & 62.1 & 6.9 & 0.06 \\
\hline
\end{tabular}

Table 7. Means of In Vivo Clearance, Volume of Distribution, \% Plasma Protein Binding, LogP and PSA. Groups were Classified Based on the Correlation Between In Vivo CL and Predicted $\mathrm{CL}_{\text {in vitro }}$ Calculated from Model A

\begin{tabular}{|c|c|c|c|c|c|c|}
\hline Group & In Vivo CL ( $\mathrm{ml} / \mathrm{min} / \mathrm{kg})$ & $\mathbf{V}_{\text {Ss }}(\mathbf{L} / \mathbf{k g})$ & \% Plasma Protein Binding & $\log P$ & PSA & \% Remaining \\
\hline Good prediction & $26.18 \pm 22.62$ & $3.52 \pm 6.02$ & $77.96 \pm 32.75$ & $3.39 \pm 1.61$ & $102 \pm 32$ & $80.47 \pm 13.90$ \\
\hline Under prediction & $49.18 \pm 27.26$ & $4.61 \pm 6.32$ & $85.95 \pm 63.39$ & $3.10 \pm 1.73$ & $99.22 \pm 33.49$ & $88.90 \pm 9.65$ \\
\hline Over prediction & $6.88 \pm 4.76$ & $1.35 \pm 1.35$ & $74.77 \pm 30.61$ & $3.41 \pm 1.62$ & $90.46 \pm 33.48$ & $76.54 \pm 14.57$ \\
\hline
\end{tabular}

Note: Mean $\pm \mathrm{SD}, \mathrm{N}=146$. 
A

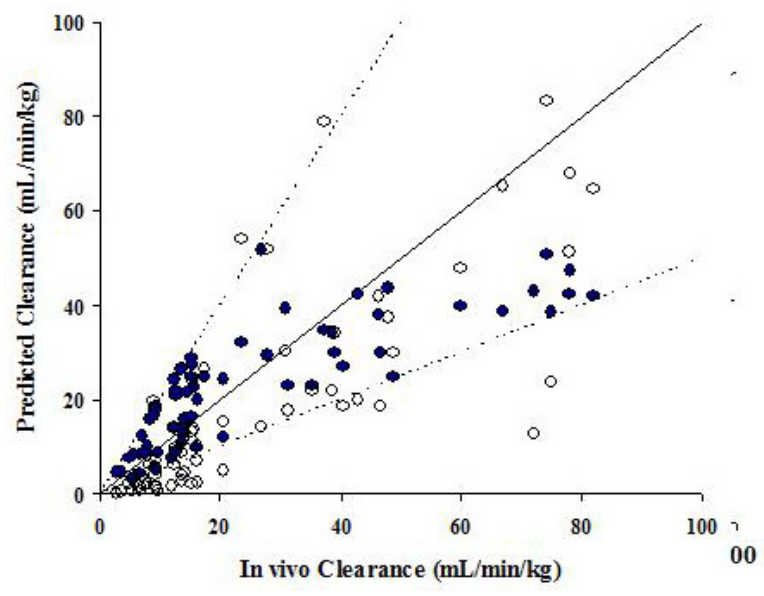

B

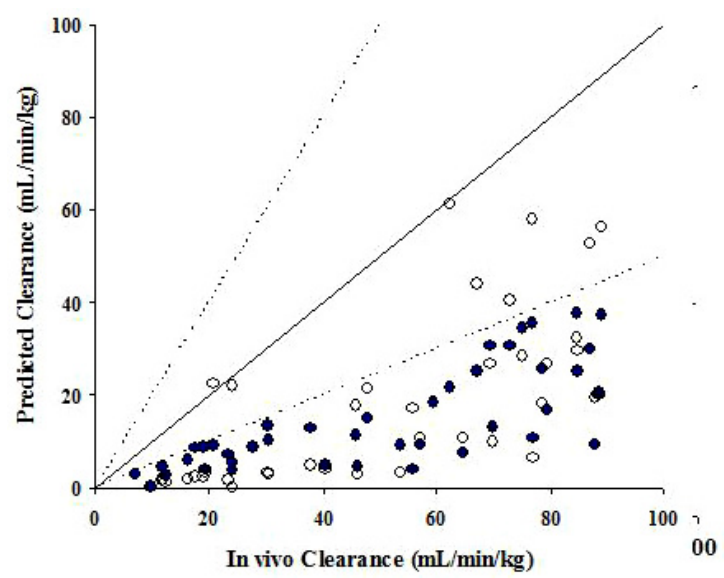

C

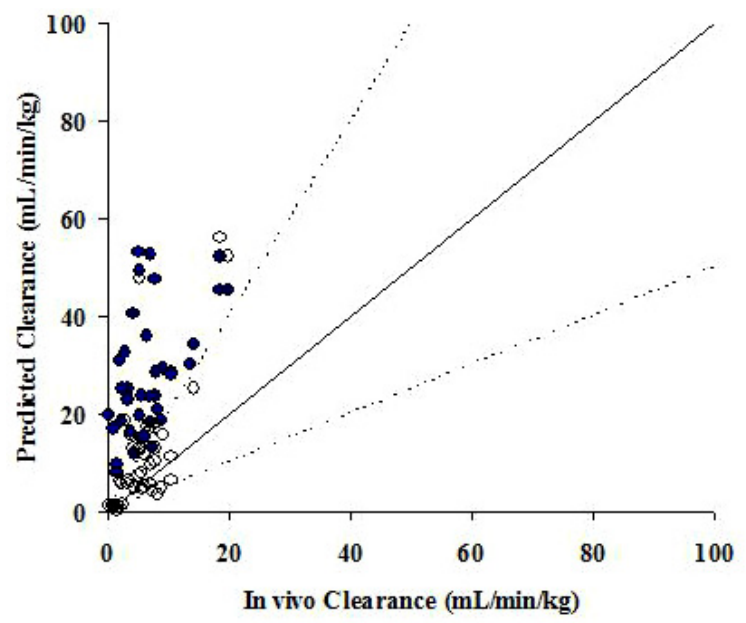

Fig. (6). Plots between in vivo $\mathrm{CL}$ and predicted $\mathrm{CL}_{\text {in vitro }}$ from mouse S9 calculated from well-stirred model $(\mathrm{N}=146)$. A, good prediction group. $\mathbf{B}$, under prediction group. $\mathbf{C}$, over prediction group. $\bullet$ represents model A and $\circ$ represents model D. Solid line represents lines of unity, and the area between the dot-lines represents an area within 2-fold error.

mined by the regression analysis to obtain the best fit between intrinsic CL in vivo and intrinsic CL in vitro. Our study showed that the ratio in vivo $\mathrm{CL} /$ predicted $\mathrm{CL}_{\text {in viro }}$ varied from 0.02 to 94 . Therefore, a single scaling factor was
A

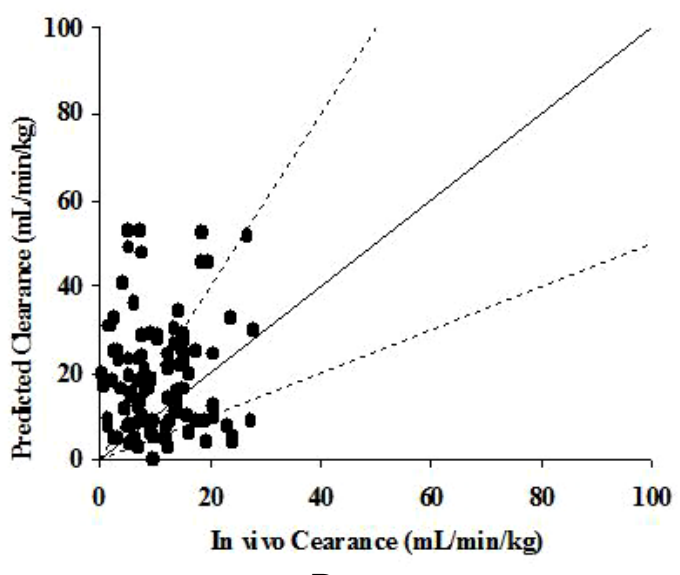

B

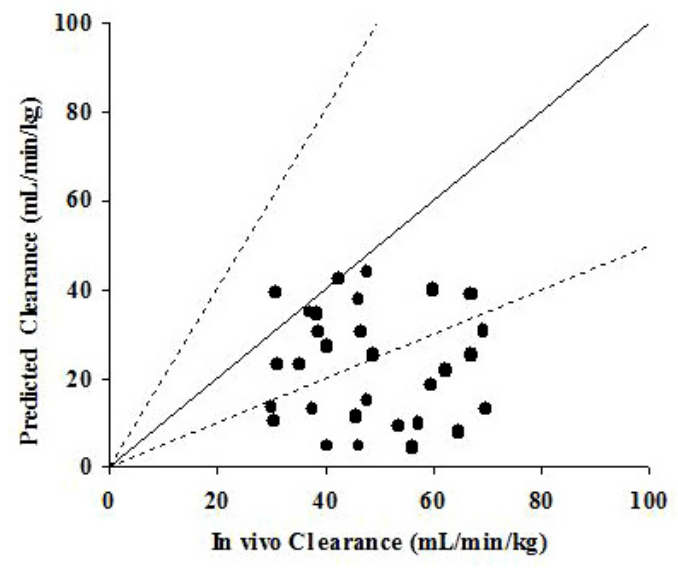

C

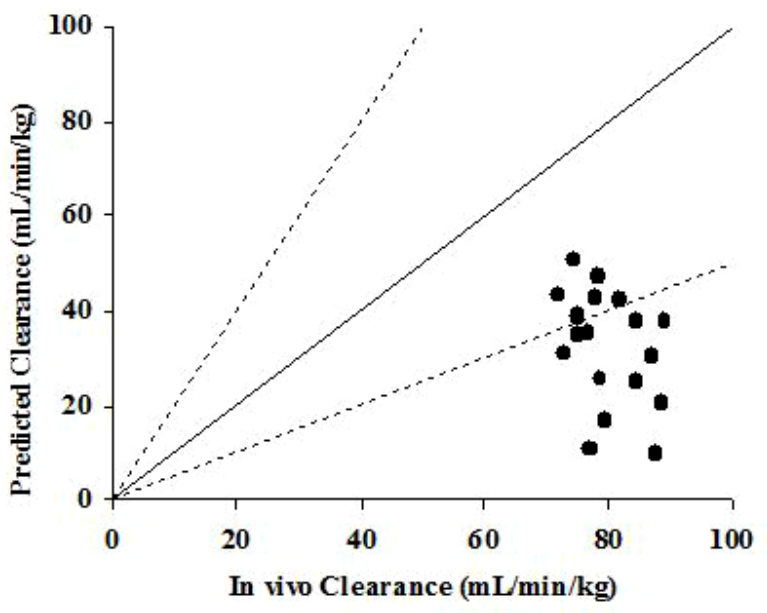

Fig. (7). Plots between in vivo $\mathrm{CL}$ and predicted $\mathrm{CL}_{\text {in viro }}$ from mouse S9 using model A (N=146). A, CL $<30 \mathrm{~mL} / \mathrm{min} / \mathrm{kg}$. B, CL $30-70 \mathrm{~mL} / \mathrm{min} / \mathrm{kg}$. C, CL $>70 \mathrm{~mL} / \mathrm{min} / \mathrm{kg}$. Solid line represents lines of unity, and the area between the dot-lines represents an area within 2-fold error.

not applicable to the structural diversity of the compounds used in our study or typically investigated in drug discovery.

The apparent poor agreement in our study between in vivo $\mathrm{CL}$ and predicted $\mathrm{CL}_{\text {in vitro }}$ was similar to the observation of some others using microsomes, hepatocytes and S-9 from humans or rats. For example, Andersson et al. presented the 
Table 8. Classification of 146 Compounds Based on In Vivo CL. Percentages of Compounds Falling into Good Prediction, Under Prediction and Over Prediction and r Values Using Model A

\begin{tabular}{|c|c|c|c|c|}
\hline \multirow{2}{*}{ In Vivo Clearance } & \multicolumn{3}{|c|}{ \% of Compounds } \\
\cline { 2 - 5 } & Good Prediction & Under Prediction & Over Prediction \\
\hline \hline$<30 \mathrm{~mL} / \mathrm{min} / \mathrm{kg}(\mathrm{N}=97)$ & 53.7 & 15.9 & 47.6 & - \\
$30-70 \mathrm{~mL} / \mathrm{min} / \mathrm{kg}(\mathrm{N}=30)$ & 30.8 & 26.9 & -0.011 \\
$>70 \mathrm{~mL} / \mathrm{min} / \mathrm{kg}(\mathrm{N}=19)$ & 23.8 & 66.7 & -0.039 \\
\hline
\end{tabular}

prediction of hepatic CL using well-stirred model and $\mathrm{CL}_{\text {int }}$ calculated from enzyme kinetic measurement. Three out of four compounds showed under, and overestimation of in vivo CL when including and excluding plasma protein binding [7]. Carlile et al. reported poor predicted $\mathrm{CL}_{\text {int }}$ of some CYP2C9 substrates using human microsomes with the predicted/observed $\mathrm{CL}_{\text {int }}$ ratios of 0.05-0.31 [17]. Masimiremnwa et al. found no correlation between in vitro half life in rat liver S-9 and measured blood CL in vivo of 48 compounds in the same chemical series [18]. Thus our results appear to be in agreement with the studies that have not shown good agreement between predicted $\mathrm{CL}_{\text {in vitro }}$ and in vivo $\mathrm{CL}$ with a larger number of compounds and various chemotypes.

\section{CONCLUSION}

This study was specifically designed to investigate the utility of the high throughput metabolic stability assay to generate an estimate of $\mathrm{CL}_{\mathrm{int}}$, in vitro and to estimate in vivo CL. The metabolic stability assay is run in generally high throughput mode over a wide range of chemical diversity and metabolic stability. Therefore if this approach is to have utility in estimating in vivo CL it must have generic applicability, robustness and accuracy in the prediction of in vivo $\mathrm{CL}$. The results of our studies suggest that $\mathrm{CL}_{\text {int, in vitro }}$ calculated from metabolic stability data obtained using mouse liver S9 could not reliably predict in vivo CL. The data in the literature is inconsistent in regard to the utility of predicting in vivo $\mathrm{CL}$ from $\mathrm{CL}_{\mathrm{int}}$, in vitro with reports showing both good and poor agreement. It is not readily apparent why these differences appear to exist in the literature in regard to the utility of $\mathrm{CL}_{\mathrm{int}}$, in vitro to predict in vivo CL. In our studies it was also not readily obvious why some compounds did appear to correlate with in vivo CL data, and others did not. Certainly, some studies do suggest that inclusion of a scaling factor can improve the correlation [12]. However, it remains unclear whether such scaling factors have generic applicability or are chemotype specific. From our studies with a large number of chemicals and using diverse chemotypes, there does not appear to be a common scaling factor. If such scaling factors are chemotype specific, then their utility would be restrictive and would not meet the criteria for use of high throughput metabolic stability screening data in providing as estimate of in vivo CL. However, overall the results from our studies suggest that in vitro metabolic data from mouse liver S9 does not reliably predict in vivo metabolic CL. It is also not clear from the literature, whether metabolic stability data from other in vitro hepatic systems can be used reliably to predict in vivo $\mathrm{CL}$ over a diverse range of chemical entities. In conclusion, the currently employed in vitro high throughput screening approaches for the determination of metabolic stability do not appear to reliably predict in vivo CL.

\section{ACKNOWLEDGMENTS}

We thank James Schmidt for mass spectrometry and Eric Buxton for data collection from Abase.

\section{ABBREVIATIONS}

$\begin{array}{ll}\text { b.w. } & =\text { Body weight } \\ \mathrm{CL} & =\text { Clearance } \\ \mathrm{CL}_{\text {in vitro }} & =\text { Intrinsic clearance } \\ \mathrm{CL}_{\text {int }} & =\text { In vitro intrinsic clearance } \\ \mathrm{CL}_{\text {int, } \text { in vitro }} & =\text { Fraction unbound in plasma } \\ \mathrm{f}_{\mathrm{u}, \text { plasma }} & =\text { Fraction unbound in } \mathrm{S} 9 \\ \mathrm{f}_{\mathrm{u}, \mathrm{S} 9} & =\text { Intravenous } \\ \mathrm{IV} & =\text { Polar surface area } \\ \mathrm{PSA} & =\text { Pharmacokinetics } \\ \mathrm{PK} & =\text { Pharmacodynamics } \\ \mathrm{PD} & =\text { Hepatic blood flow } \\ \mathrm{Q}_{\mathrm{h}} & =\text { Scaling factor } \\ \mathrm{SF} & =\text { Half life } \\ \mathrm{t}_{1 / 2} & =\text { Volume of distribution at the steady state } \\ \mathrm{VsS} & \end{array}$

\section{REFERENCES}

[1] Adams, C.P.; Brantner, V.V. Estimating the cost of new drug development: is it really 802 million dollars? Health Aff. (Millwood), 2006, 25(2), 420-8.

[2] Kerns, E.H.; Di, L. Pharmaceutical profiling in drug discovery. Drug Discov. Today, 2003, 8(7), 316-23.

[3] Obach, R.S.; Baxter, J.G.; Liston, T.E.; Silber, B.M.; Jones, B.C. MacIntyre, F.; Rance, D.J.; Wastall, P. The prediction of human pharmacokinetic parameters from preclinical and in vitro metabolism data. J. Pharmacol. Exp. Ther., 1997, 283(1), 46-58.

[4] Ito, K.; Houston, J.B. Comparison of the use of liver models for predicting drug clearance using in vitro kinetic data from hepatic microsomes and isolated hepatocytes. Pharm. Res., 2004, 21(5), 785-92.

[5] Bayliss, M.K.; Bell, J.A.; Jenner, W.N.; Park, G.R.; Wilson, K. Utility of hepatocytes to model species differences in the metabolism of loxtidine and to predict pharmacokinetic parameters in rat, dog and man. Xenobiotica, 1999, 29(3), 253-68.

[6] Iwatsubo, T.; Hirota, N.; Ooie, T.; Suzuki, H.; Shimada, N.; Chibi, K.; Ishizaki, T.; Green, C.E.; Tyson, C.A.; Sugiyama, Y. Prediction of in vivo drug metabolism in the human liver from in vitro metabolism data. Pharmacol. Ther., 1997, 73(2), 147-71.

[7] Andersson, T. B.; Bredberg, E.; Ericsson, H.; Sjoberg, H. An evaluation of the in vitro metabolism data for predicting the clear- 
ance and drug-drug interaction potential of CYP2C9 substrates. Drug Metab. Dispos., 2004, 32(7), 715-21.

[8] Obach, R.S. Prediction of human clearance of twenty-nine drugs from hepatic microsomal intrinsic clearance data: An examination of in vitro half-life approach and nonspecific binding to microsomes. Drug Metab. Dispos., 1999, 27(11), 1350-9.

[9] Davies, B.; Morris, T. Physiological parameters in laboratory animals and humans. Pharm. Res., 1993, 10(7), 1093-5.

[10] Brown, R.P.; Delp, M.D.; Lindstedt, S.L.; Rhomberg, L.R.; Beliles, R.P. Physiological parameter values for physiologically based pharmacokinetic models. Toxicol. Ind. Health, 1997, 13(4), 407-84.

[11] Naritomi, Y.; Terashita, S.; Kimura, S.; Suzuki, A.; Kagayama, A.;Sugiyama, Y. Prediction of human hepatic clearance from in vivo animal experiments and in vitro metabolic studies with liver microsomes from animals and humans. Drug Metab. Dispos., 2001, 29(1), 1316-24.

[12] Ito, K.; Houston, J.B. Prediction of human drug clearance from in vitro and preclinical data using physiologically based and empirical approaches. Pharm. Res., 2005, 22(1), 103-12.

[13] Obach, R.S. Nonspecific binding to microsomes: impact on scaleup of in vitro intrinsic clearance to hepatic clearance as assessed through examination of warfarin, imipramine, and propranolol. Drug Metab. Dispos., 1997, 25(12), 1359-69.

[14] Li, L.; Sarawek, S.; Yu, X.Q.; Nouraldeen, A.; Rooney, S.; Moran, L.; Wilson, A.G.E. The utility of in vitro metabolic stability to estimate in vivo clearance. The 2008 Annual Meeting and Exposition; Atlanta, GA, 2008.

[15] Riley, R.J.; McGinnity, D.F.; Austin, R.P. A unified model for predicting human hepatic, metabolic clearance from in vitro intrinsic clearance data in hepatocytes and microsomes. Drug Metab. Dispos., 2005, 33(9), 1304-11.

[16] Clarke, S.E.; Jeffrey, P. Utility of metabolic stability screening: comparison of in vitro and in vivo clearance. Xenobiotica, 2001 31(8-9), 591-8.

[17] Carlile, D.J.; Hakooz, N.; Bayliss, M.K.; Houston, J.B. Microsomal prediction of in vivo clearance of CYP2C9 substrates in humans. Br. J. Clin. Pharmacol., 1999, 47(6), 625-35.

[18] Masimirembwa, C.M.; Bredberg, U.; Andersson, T.B. Metabolic stability for drug discovery and development: pharmacokinetic and biochemical challenges. Clin. Pharmacokinet, 2003, 42(6), 515-28.

(c) Sarawek et al.; Licensee Bentham Open.

This is an open access article licensed under the terms of the Creative Commons Attribution Non-Commercial License (http://creativecommons.org/licenses/by-nc/3.0/) which permits unrestricted, non-commercial use, distribution and reproduction in any medium, provided the work is properly cited. 